\title{
Mechanical Aspects of Construction of New TBM Tunnel Under Existing Structures
}

\author{
Wu Ke $\cdot$ Zhang zheng $\cdot$ Li Shuchen $\cdot$ Zhou leisheng $\cdot$ Zhao Jiahui $\cdot$ \\ Zheng Yang
}

Received: 29 January 2021 / Accepted: 22 May 2021/Published online: 28 May 2021

(C) The Author(s) 2021

\begin{abstract}
It is inevitable for the construction of subways to pass under the existing structures in the city; this will cause settlement of the existing structures and affect their safety. The soil is a complex mixture, and hence it is difficult to determine the damage caused by construction using tunnel boring machine (TBM) method to the stress balance of the surrounding soil. Normally, settlement and uplift of the surface are caused during tunneling. Therefore, large-scale 3D simulations are needed to study the interaction between mechanically driven tunnel construction and the surrounding soil to estimate the
\end{abstract}

W. Ke $\cdot$ Z. zheng $(\bowtie) \cdot$ Z. Jiahui $\cdot$ Z. Yang

School of Civil Engineering, Shandong University, Jinan, China

e-mail: 15230816905@163.com

W. Ke

e-mail: wuke@sdu.edu.cn

Z. Jiahui

e-mail: 978715768@qq.com

Z. Yang

e-mail: 1010073862@qq.com

L. Shuchen

School of Qilu Transportation, Shandong University, Jinan, China

e-mail: shuchenli@sdu.edu.cn

Z. leisheng

Construction Management Branch, Qilu Transportation

Development Group Co., Ltd, Jinan, China

e-mail: qianjindyx@126.com expected settlement and related damage risks to the existing structures, especially in tunnel construction in urban areas. Qingdao Metro Line 1 in the Haixiao section (Xiaocunzhuang and Haiboqiao stations) was taken up as the research object to study the trend and degree of the effect of TBM tunnel construction using the numerical simulation software Midas GTS NX. The numerical simulation results and measured data were used for the reliability analysis to study the influence of different digging speeds and pressures in TBM construction on ground subsidence, and the effect of vibrations generated at the tunnel face by the TBM cutter head on the ground structure. It is shown that when other factors remain unchanged, the faster the driving speed, the smaller the ground settlement; the higher the surrounding rock pressure, the smaller the ground settlement. The vibration of the ground structure caused by the TBM cutter head complies with the relevant specifications. During construction, the driving parameters should be selected suitably depending on the available budget.

Keywords TBM tunnel - Tunneling projects . Numerical simulation $\cdot$ Measured data $\cdot$ Mechanical mechanism 


\section{Introduction}

With China's economic development, many Chinese cities have begun to construct or expand the subway lines. An urban subway route inevitably undercuts the existing structures. Different regions have various geological conditions and subway construction methods. At present, the shield method is mainly used in soft soil layers, while the traditional drilling and blasting method and the modern tunnel boring machine (TBM) method are used in relatively hard rock and soil layers. As the project cost was low, there was sufficient experience in drilling and blasting methods, and these methods were used in hard rock and soil layers in the past. It is undeniable that the environmental impact of blasting vibrations is large, and the progress of construction is slow.

TBM has the advantages of low environmental impact and high efficiency, and is increasingly being used in subway construction units (Komu et al. 2019). The core content of the new Austrian method is to obtain the mechanical properties and changes in the surrounding rock, conduct monitoring and measurement activities at the tunnel site, and to guide the design and construction of the tunnel through timely feedback of the monitoring and measurement data (Wu et al. 2018). Among the various monitoring methods, monitoring of convergent deformation is the simplest, direct, and most widely used one. Based on past experience, a larger convergence displacement is expected near the tunnel surface. In spite of having a lower lateral stress, the increase in lateral stress ratio promotes the rupture of the surrounding rock, which results in a larger range of failure zones and more severe extrusion deformation (Aygar 2020; Liu et al. 2016). In the cross section of the tunnel, the deformation over the tunnel crown is usually the largest, and TBM jamming is normally caused when the surrounding rock over the TBM squeezes the shield ( $\mathrm{Lv}$ and Jiang 2012). Most subways are built in cities with complex structures, and the ground settlement caused by tunnel construction must be strictly controlled. TBM also causes vibration problems in construction in the urban environment, especially in residential areas, commercial areas, special units, bridges, stations, equipment, and machines that are sensitive to environmental vibrations near the tunnel sections. These problems cannot be ignored during TBM tunnel construction. The vibration intensity of the ground structures is closely related to the vibration intensity of the source, mechanical properties of the ground, and dynamic characteristics of the building or equipment (Kwak and Park 2015; Namli and Aras 2020). Under complex geological conditions, finite-difference software can be used to perform 3D simulations of TBM and the surrounding environment. Numerical analysis can be effectively used to assess the impact of unfavorable geological environments on TBM traps and to predict the performance of shield tunnels. The thrust required during excavation is estimated in advance for adverse ground conditions (Bahrainy and Khosravi 2013). Considering the TBM geometry, a comprehensive finite element analysis (FEA) was performed to simulate the TBM tunnel, and the results were verified by comparing with the monitoring results. The FEA model can simulate the excavation ground, mechanical structure, and excavation process on the site (Hasanpour et al. 2017; Liu et al. 2020; Wu et al. 2013). The torque and thrust of the boring machine are the two main design parameters of the shield TBM. The DEM can estimate the torque and thrust of the TBM by applying the actual boundary conditions and material properties of the model (Faramarzi et al. 2020). The excavation process is modeled in various ground conditions considering different velocity-torque characteristics. Zhang found that the torque required for excavation changes with the strength of the ground, and that an increase in hard surface layers increases the torque required (Zhang et al. 2010). Pirastehfar used 3D finite element method to study the mechanism of interaction between the shield tunnels driven at a close range; Shiraz metro line 2 was taken as a specific case study. It was concluded that the interaction between the tunnels driven by a close shield is controlled by geotechnical parameters such as soil stiffness, cohesion, and friction angle, and geometrically related parameters such as the distance between the tunnels (Pirastehfar et al. 2020; Yang et al. 2020). Most of the current research work focus on the deformation and surface settlement during the tunnel excavation process; only a few studies are found in the international engineering geology and rock engineering literature on the use of 3D numerical simulation software to simulate the entire construction process and analyze the impact of TBM on the construction environment from the perspective of ground vibration. 
This article analyzes the impact of TBM construction for Qingdao Metro Line 1 between the Haixiao section (Xiaocunzhuang and Haiboqiao stations) underpass and the Renmin Road overpass on the bridge structure. The vibration levels of key buildings (structures) along the line are also tested and analyzed to determine the trend and degree of the effect of TBM excavation on the ground buildings (structure). This work serves as a theoretical basis for building protection during the construction of Qingdao Rail Transit and provides valuable experience and data for TBM application in the urban environment.

\section{Project Overview}

TBM technology is used for the tunnel between Xiaocunzhuang station and Haiboqiao station on Line 1 of Qingdao Metro. The lengths of the left and right construction sections are $818.751 \mathrm{~m}$ and $648 \mathrm{~m}$, respectively. The tunnel covers the area that runs from the Haibo Bridge, north along Renmin Road to cross Nanning Road and Fushun Road, then crosses under Renmin Road overpass, and ends inside the small village station. The TBM tunnel has a standard single-hole, single-line circular cross-section. The sectional plane line is a straight section, the line spacing is $14-16 \mathrm{~m}$, the thickness of the overburden is 20-29 m, and the maximum slope of the line is $25 \%$ o (Fig. 1). The tunnel lining is made of C50 prefabricated reinforced concrete segments with an outer diameter of $6.0 \mathrm{~m}$, inner diameter of $5.4 \mathrm{~m}$, thickness of $0.3 \mathrm{~m}$, and ring width of $1.5 \mathrm{~m}$ (Fig. 2).

Drilling in the region revealed that the Quaternary in the field has a thickness of $0.40-12.20 \mathrm{~m}$ and that it is mainly composed of the Quaternary Holocene artificial fill layer (Q4 ml), Holocene alluvial layer (Q4 $\mathrm{al}+\mathrm{pl}$ ), and Upper Pleistocene alluvial silty clay layer $(\mathrm{Q} 3 \mathrm{al}+\mathrm{pl})$. The bedrock comprises the late Yanshan intrusive granite $(\gamma 53)$, local granite porphyry $(\gamma \pi 53)$, and fine-grained granite $(\gamma 53)$ veins. Owing to the effect of the faults, some boreholes are found to have corresponding lithological tectonic rocks.

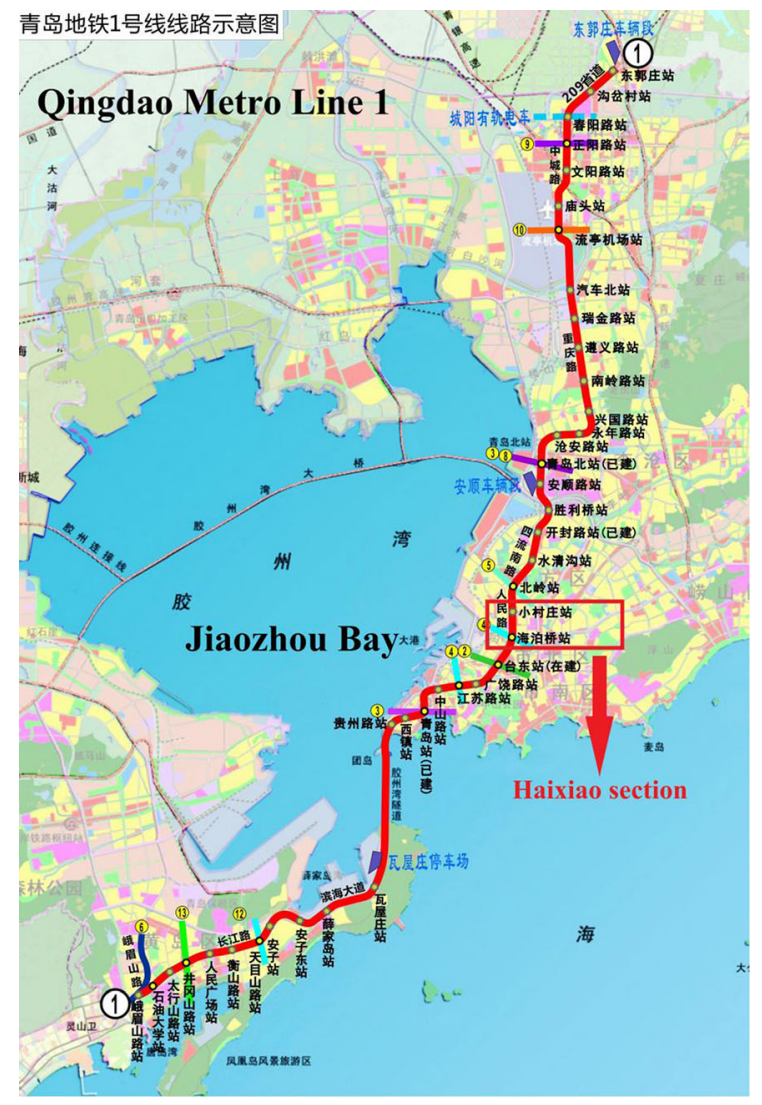

Fig. 1 Project location

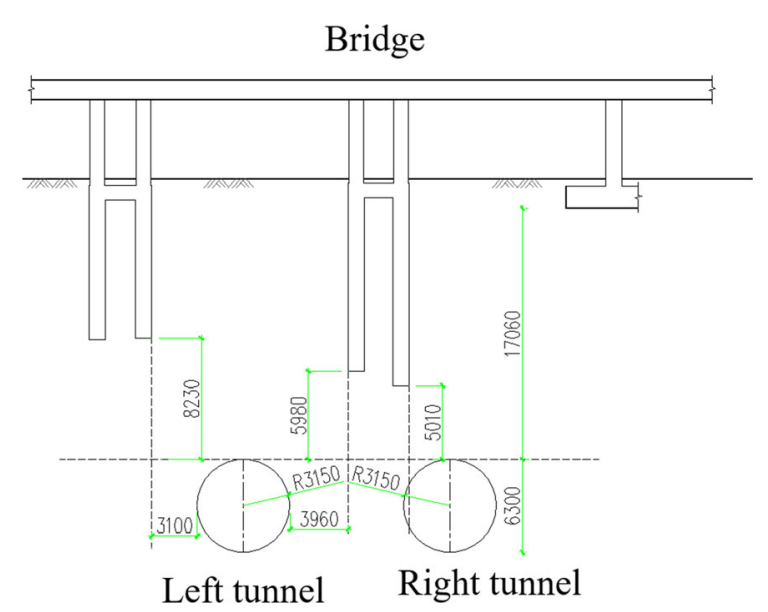

Fig. 2 Geometrical dimensions of the tunnel side through structure 


\section{Calculation Model}

\subsection{Simulation of TBM Excavation}

In TBM excavation, the hob rotates under thrust, and the rock of the palm face breaks under the strong thrust and torque. After the rock is broken, the initial in-situ stress on the excavation surface is relieved. Therefore, this process is equivalent to the digging and breaking of the rock by excavating and unloading to simulate the TBM (Rezaei and Ahmadi-adli 2020). Assuming that the unloading process is linear, the TBM excavation construction can be simulated by linearly removing the load when normal driving pressure and jack load are applied on the tunnel wall within a certain time. Midas GTS NX software is used to simulate the TBM tunneling process. The locations of points DC1 to DC4 in the model are shown in Figs. 3 and 5.

Considering the relevant engineering experience and theories, the relevant model size effect is considered. The distance from the left and right boundaries of the tunnel to the edge in the model must be approximately 3D-5D. From the far boundary, this value will not be affected by excavation. If the model size is small, then the calculation result will be inaccurate (Yang et al. 2019). In the model, the diameter of the shield tunnel is $6 \mathrm{~m}$, the thickness of the segment is $0.3 \mathrm{~m}$, and the shield segment length is $1.5 \mathrm{~m}$. The geometric size of the model is the same as that of the surrounding rock with dimensions of $90 \mathrm{~m} \times 50 \mathrm{~m} \times$ $50 \mathrm{~m}$. The corresponding calculation model is shown in Figs. 4 and 5.

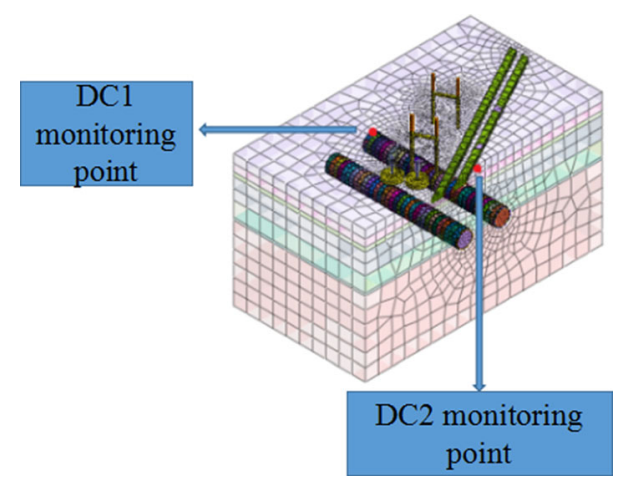

Fig. 3 Layout of monitoring points

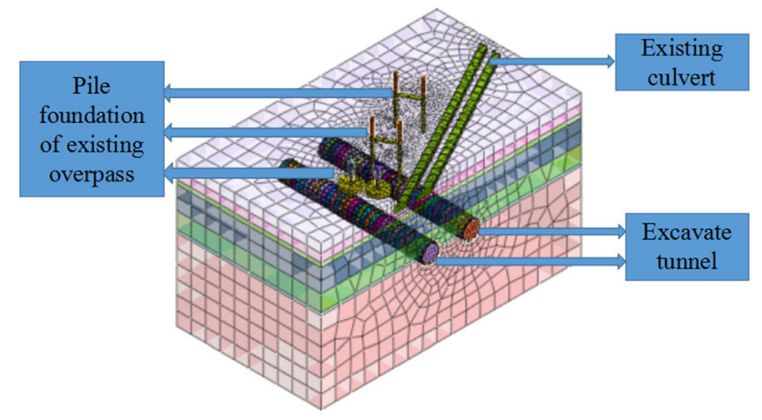

Fig. 4 Model and stratigraphic division

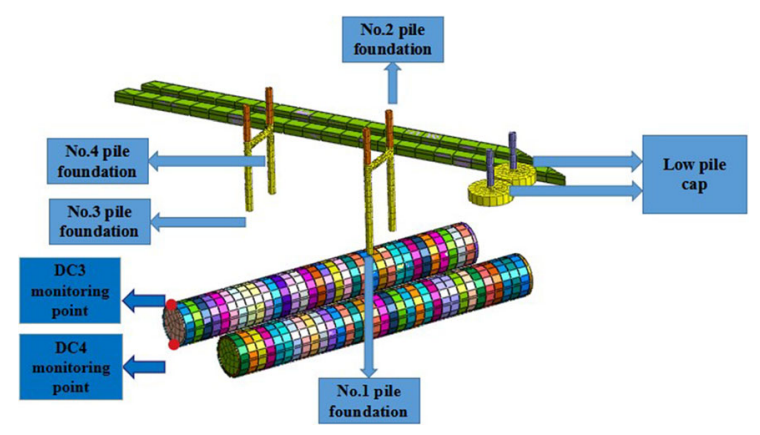

Fig. 5 Tunnel and location with respect to surrounding structures

\subsection{Model Parameter Selection}

The modified Mohr-Coulomb model is used for the soil layer. Segments, bridges, and segment grouting are considered as solid units in the model. The plate unit is used for simulation to establish the shield shell and underdrain pipeline modules, as it allows easy calculation of the model structure coupling. Based on the on-site geological survey and numerical simulation experience, the model parameters are selected; these are listed in Table 1.

\subsection{Simulation Method}

The model considers only the vibration due to the breakage of the rock by the cutter head and not the mechanical vibration of the TBM main engine and bolt drilling operation (Ling et al. 2018). In the analysis of the sensitivity of different driving speeds, the average driving speed is $2.30 \mathrm{~m} / \mathrm{h}$ for the TBM for the crossing of the slightly weathered granite layer (Li et al. 2012). In agreement with the on-site tunneling data, the 
Table 1 Mechanical parameters of geotechnical media in the model

\begin{tabular}{|c|c|c|c|c|c|}
\hline Material & $\begin{array}{l}\text { Elastic modulus } \\
(\mathrm{MPa})\end{array}$ & $\begin{array}{l}\text { Poisson's } \\
\text { ratio }\end{array}$ & $\begin{array}{l}\text { Volumetric weight } \\
\left(\mathrm{kN} / \mathrm{m}^{3}\right)\end{array}$ & $\begin{array}{l}\text { Cohesive forces } \\
(\mathrm{kPa})\end{array}$ & $\begin{array}{l}\text { Friction angle } \\
\left({ }^{\circ}\right)\end{array}$ \\
\hline Miscellaneous fill & 6.0 & 0.30 & 17.5 & 19.0 & 12 \\
\hline Silty clay & 10.0 & 0.30 & 19.9 & 22.6 & 25 \\
\hline Medium-coarse sand & 20.0 & 0.30 & 18.5 & 34.7 & 30 \\
\hline $\begin{array}{l}\text { Upper subzone of strong weathered } \\
\text { granite }\end{array}$ & 45.0 & 0.35 & 22.5 & 30.0 & 33 \\
\hline $\begin{array}{l}\text { Lower subzone of strong weathered } \\
\text { granite }\end{array}$ & 50.0 & 0.36 & 23.0 & 30.0 & 35 \\
\hline Middle zone of weathered granite & $4.5^{*} 10^{3}$ & 0.40 & 25.0 & 80.0 & 37 \\
\hline Micro-weathered granite & $1.2 * 10^{4}$ & 0.45 & 26.7 & 120 & 40 \\
\hline Segment/bridge & $3.35 * 10^{4}$ & 0.4 & 23.87 & & \\
\hline Shield shell & $2.06 * 10^{4}$ & 0.4 & 78.5 & & \\
\hline Pier & $3.35 * 10$ & 0.4 & 23.76 & & \\
\hline
\end{tabular}

simulation of TBM tunneling process for $1 \mathrm{~m}$ takes approximately $1400 \mathrm{~s}, 1700 \mathrm{~s}, 2000 \mathrm{~s}, 2300 \mathrm{~s}$, and $2600 \mathrm{~s}$ for digging speeds of $2.55 \mathrm{~m} / \mathrm{h}, 2.11 \mathrm{~m} / \mathrm{h}$, $1.8 \mathrm{~m} / \mathrm{h}, 1.56 \mathrm{~m} / \mathrm{h}$, and $1.38 \mathrm{~m} / \mathrm{h}$, respectively. These speed values are used to study the impact of different TBM construction digging speeds on ground settlement. For the sensitivity analysis of different driving pressures, construction reports and on-site measurements revealed that the driving pressures to be used in the TBM driving simulation are $120 \mathrm{kN} / \mathrm{m}^{2}, 240 \mathrm{kN} /$ $\mathrm{m}^{2}, 360 \mathrm{kN} / \mathrm{m}^{2}, 480 \mathrm{kN} / \mathrm{m}^{2}$, and $600 \mathrm{kN} / \mathrm{m}^{2}$.

\subsection{Shield Simulation Construction Steps}

The actual TBM construction process is complicated. In this study, the steps are simplified with some approximation for the simulation, and the later consolidation and rheology of the soil are not considered. The main loads applied are shown in Fig. 6.

For simulating the construction, two segments with a size of $3 \mathrm{~m}$ are required as a construction step; the excavation is conducted first on the left line and then on the right line. A total of 36 construction steps are performed on the left and right lines, and each construction step is a circular excavation process. The model simulation of TBM construction consists of four main steps. The first is to generate an initial stress field; the second is to simulate different TBM driving speeds; the third is to simulate different TBM driving pressures; and the fourth is to simulate the effect of the vibration generated by the TBM cutter head (while driving into the tunnel face) on the vibration of the ground structures. The first, second, and third steps are solved by static mode, and the fourth step is solved by eigenvalue analysis and non-linear time history analysis (direct integration method) in the software. In the various solution modes, the boundary conditions of the model are set differently. In the static mode solution, the bottom boundary nodes remain unchanged for the fully constrained model; both ends of the model are set as static boundaries at both ends of the normal constrained model during the vibration analysis stage, and the bottom boundary conditions of the model (Sun and Yang 2019).

\section{Reliability Verification}

On-site monitoring data show that the total thrust in the Haixiao section is in the range of $133-266 \mathrm{~N} / \mathrm{m}^{2}$, and the driving speed is in the range of $0.6-2.4 \mathrm{~m} / \mathrm{h}$.

Figures 7 and 8 show that the actual monitoring data and numerical simulation data have the same change trend, and that the settlement values are not significant. The settlement at DC1 decreases with the progress of excavation steps, and the settlement curve at DC2 is similar in both the monitoring and simulation data. Owing to various accidental factors in the actual project that affect the settlement value, the actual settlement on site is more than the simulated 


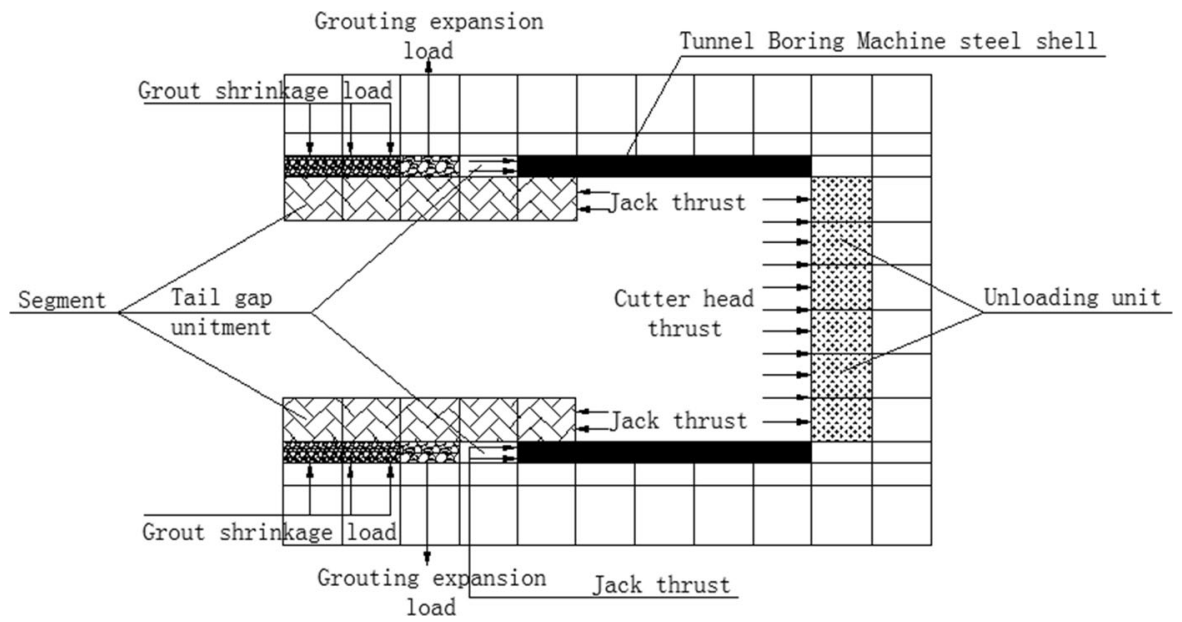

Fig. 6 Mechanical loads during TBM operation

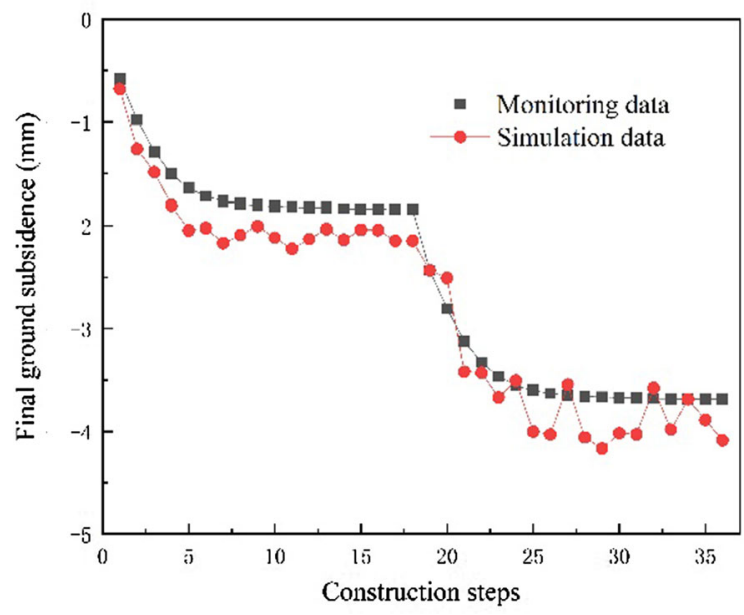

Fig. 7 Settlement curve at DC1

value. The settlement is large, but within the allowable safety range, and the maximum error is $10.7 \%$. It can be seen from the figures that at DC1 and DC2, the surface settlement obtained by the finite element calculation and the actual measurement are approximately the same. Thus, the two values agree well, indicating that it is feasible to use numerical simulation to analyze the TBM construction process.

\section{Sensitivity Analysis}

In the TBM construction, the surrounding soil is disturbed during the forward movement, as manifested by ground subsidence and deformation. The ground

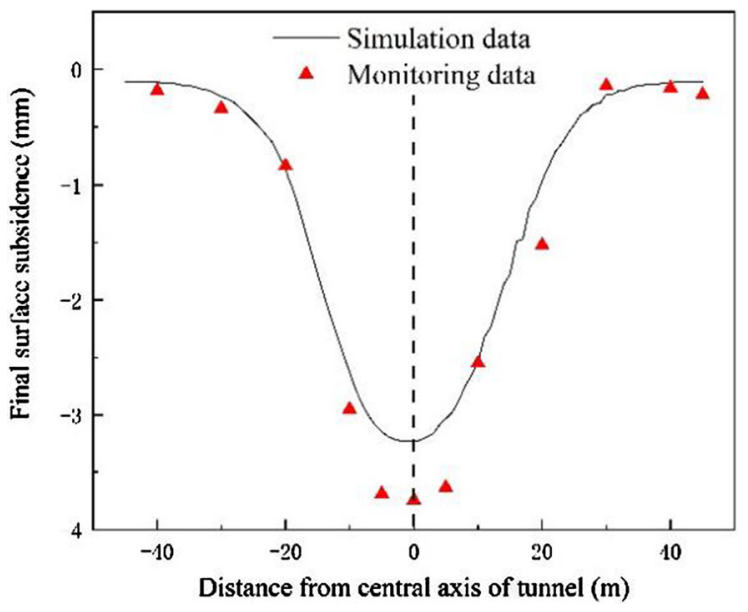

Fig. 8 Settlement curve at DC2

surface deformation during the TBM operation is mainly manifested in three aspects: The deformation of the ground when the TBM cutter head reaches the tunnel face; the deformation of the ground when the TBM cutter head reaches and passes through the tunnel face; and consolidation at the later stage of the surface (Avunduk and Copur 2019).

\subsection{Effect of Driving Speed}

The variation in the final settlement of the ground surface under different driving speeds is shown in Fig. 9. The entire surface of the tunnel is under sinking state during the tunnel excavation, and the largest surface settlement occurs at the axis of the tunnel. 


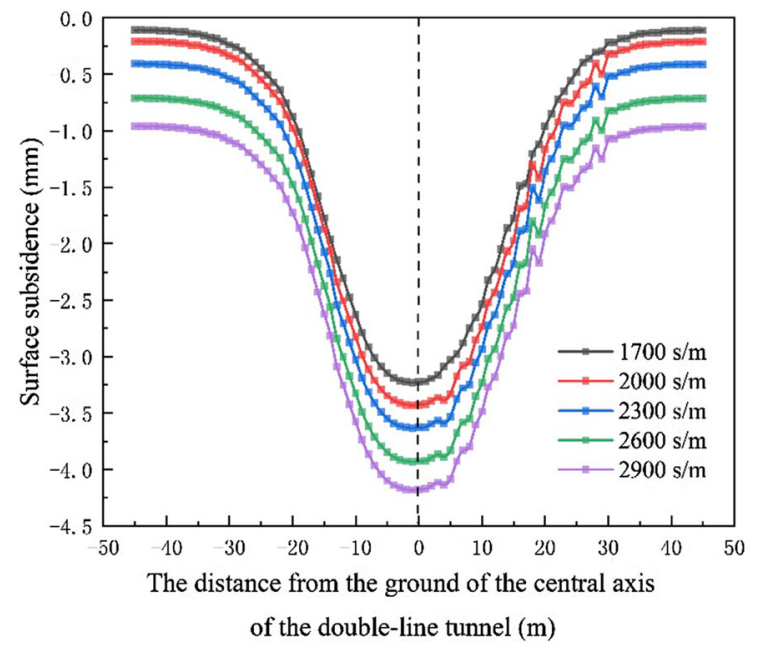

Fig. 9 Final settlement of the ground

Although the tunnel is constructed by double-line excavation, no two settlement grooves are symmetrical about the central axis on the surface, because the tunnel has a large burial depth, and the effect of the double-line tunnel excavation on ground settlement is weakened. The subsidence of the ground surface approximately $30 \mathrm{~m}$ away from the central axis of the tunnel is within $1 \mathrm{~mm}$, which has minimal influence on the ground. The surface subsidence starts increasing sharply when the distance is less than $30 \mathrm{~m}$. The figure shows that when the driving speed is $1700 \mathrm{~s} / \mathrm{m}$ $(2.55 \mathrm{~m} / \mathrm{h}), 2000 \mathrm{~s} / \mathrm{ms}(2.11 \mathrm{~m} / \mathrm{h}), 2300 \mathrm{~s} / \mathrm{ms}(1.8 \mathrm{~m} /$ h), $2600 \mathrm{~s} / \mathrm{m}(1.56 \mathrm{~m} / \mathrm{h})$, and $2900 \mathrm{~s} / \mathrm{m}(1.38 \mathrm{~m} / \mathrm{h})$, the surface settlement of the central axis is $3.22,3.43$, 3.63, 3.96, and $4.18 \mathrm{~mm}$, respectively. Tunneling speed has an effect on the surface settlement; the settlement is small when the tunneling speed is high. To maximize the economic benefits in the TBM construction, the driving speed should be increased as much as possible (with control of other driving parameters) to reduce the ground subsidence and the impact on the surface structures (Arbabsiar et al. 2020).

\subsection{Effect of Heading Pressure}

According to the relevant literature (Nagel and Meschke 2011), subsidence occurs on the surface when the earth pressure is less than the active earth pressure, as shown in Fig. 10. When the earth pressure is greater than its passive value, the earth's surface may exhibit an uplift. When the earth pressure is between its active and passive values, the ground surface neither sinks nor swells. In soft to plastic clay, a reasonable value of pressure $(P)$ can be determined according to the following equation.

$P=k \cdot \gamma \cdot H$

where $k$ is the earth pressure coefficient which is normally in the range of $0.35-0.75 ; \gamma$ is the bulk density (weighted average) of the soil layer above the centerline of the shield; and $H$ is the vertical distance of the central axis of the shield tunnel from the natural ground, and the unit is meters.

The graphs of the maximum settlement of the surface of the two tunnels and the centerline of the left and right tunnels under different driving pressures are shown in Figs. 11, 12, 13 and 14. With the increase in tunneling pressure, the maximum settlement of the surface of the tunnel center also increases. However, the settlement rate decreases first, suddenly increases after the 18th construction step, and then continues to decrease. This phenomenon occurs because the TBM construction in this section is conducted first on the left line and then on the right line, with the right-line excavation as the 18th construction step. As the construction of the left-line tunnel progresses, the surface settlement of the left-line tunnel is greater than that of the right-line tunnel; when the construction of the left-line tunnel is completed, the surface settlement value tends to stabilize; When the right-line tunnel is excavated, the later-excavated right-line tunnel will continue to cause the settlement of the surface soil in the center line of the left-line tunnel, and the left-line tunnel that has been excavated will cause the displacement field of the surrounding rock and soil of the right-line tunnel. The change has a certain impact on the construction of the right-line tunnel, causing the ground settlement during the construction of the rightline tunnel to be significantly greater than that of the single-line tunnel excavation, and the mutual disturbance effect of the two-line shield excavation is obvious. During the excavation of the left line, the maximum settlement line of the surface is always near the left tunnel surface. When the right line is excavated, the maximum settlement line of the surface is close to the surface of the center axis of the right line tunnel, thereby causing the maximum settlement of the ground on the central axis of the left and right tunnels to increase suddenly. A comparison of the 


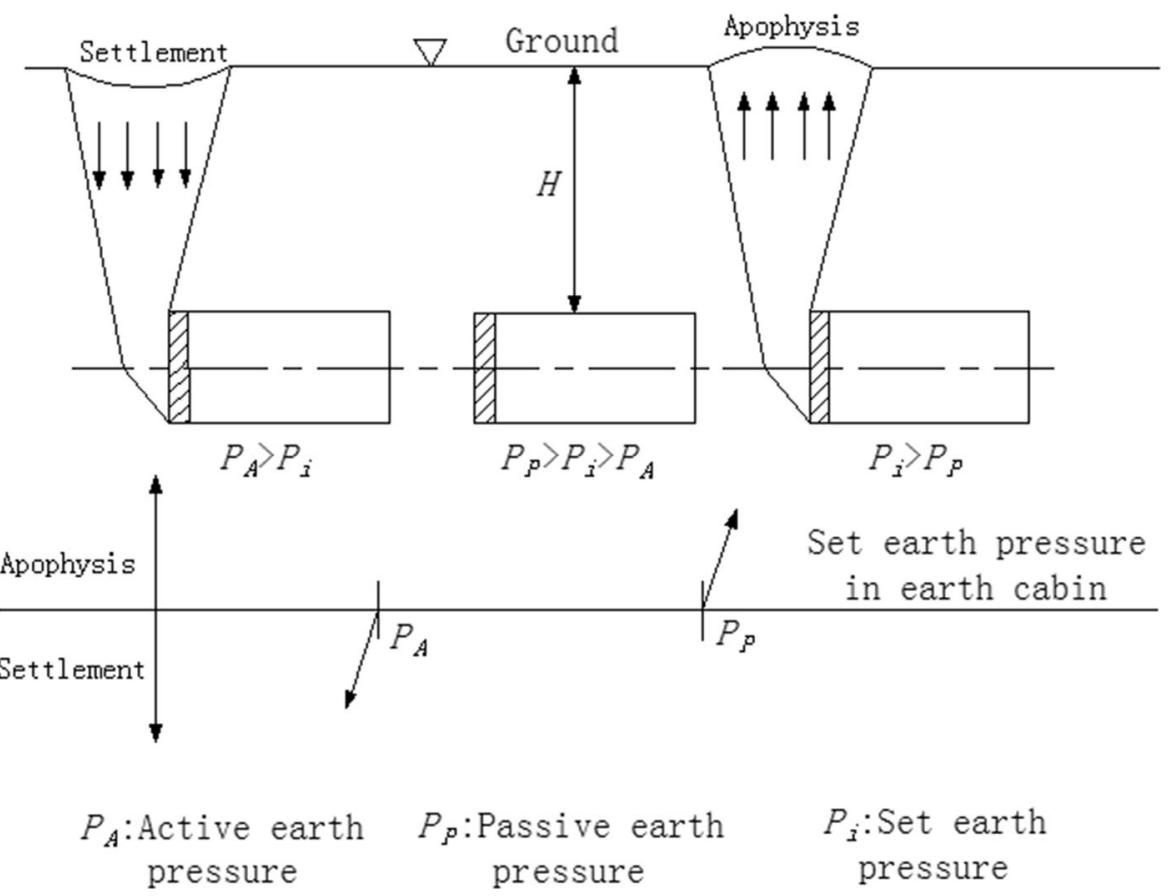

Fig. 10 Diagram showing the relationship between the set pressure of the earth cabin and the ground settlement

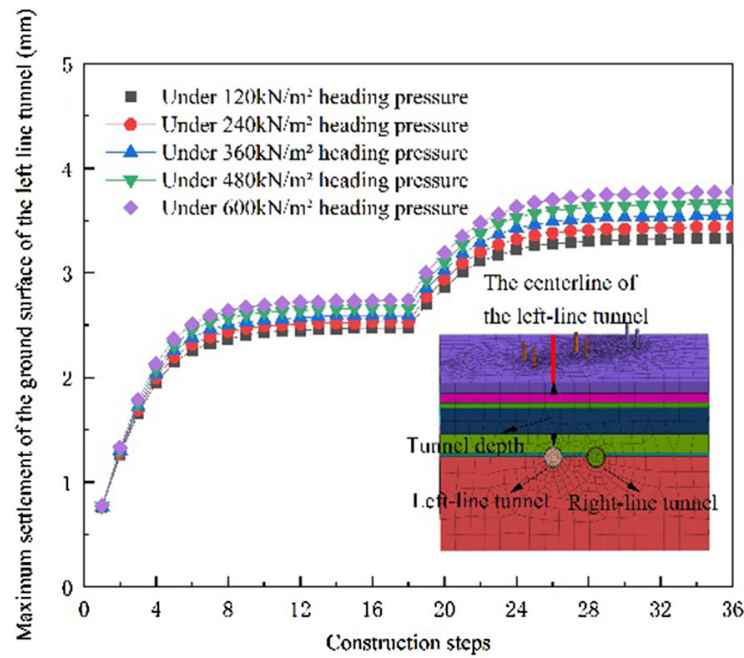

Fig. 11 Maximum surface settlement at the centerline of the left-line tunnel

maximum settlement curves on the surfaces of the left and right tunnels shows that when the tunneling pressure is $600 \mathrm{kN} / \mathrm{m}^{2}$, the maximum settlement values in the last construction step are $4.23 \mathrm{~mm}$, $3.77 \mathrm{~mm}$, and $3.66 \mathrm{~mm}$. These values indicate that increasing the tunneling pressure increases the maximum settlement of the surface centerline; the double-

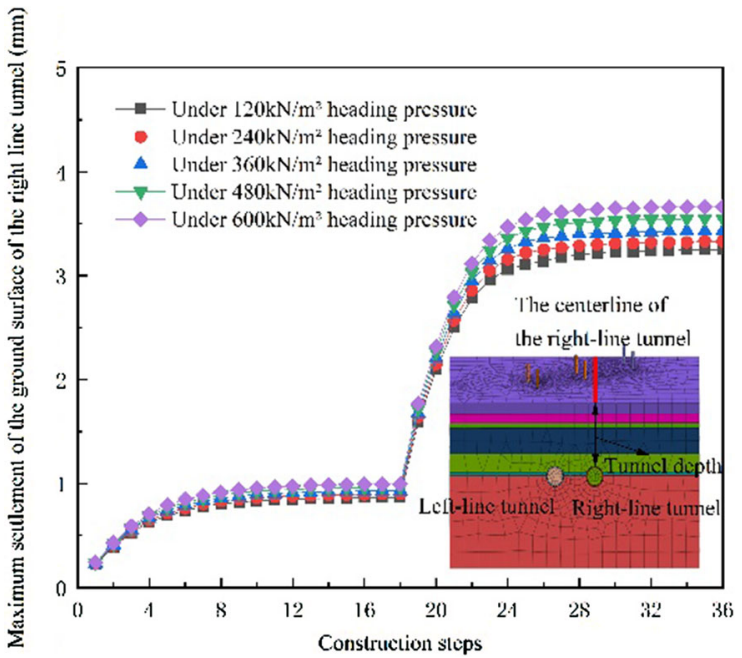

Fig. 12 Maximum surface settlement at the centerline of the right-line tunnel

line shield construction has the strongest influence on the surface settlement value of the centerline of the double-line tunnel. this should be avoided in actual projects to prevent damage to sensitive buildings on the surface of the midline of the double-lane tunnel and avoid potential safety hazards. 


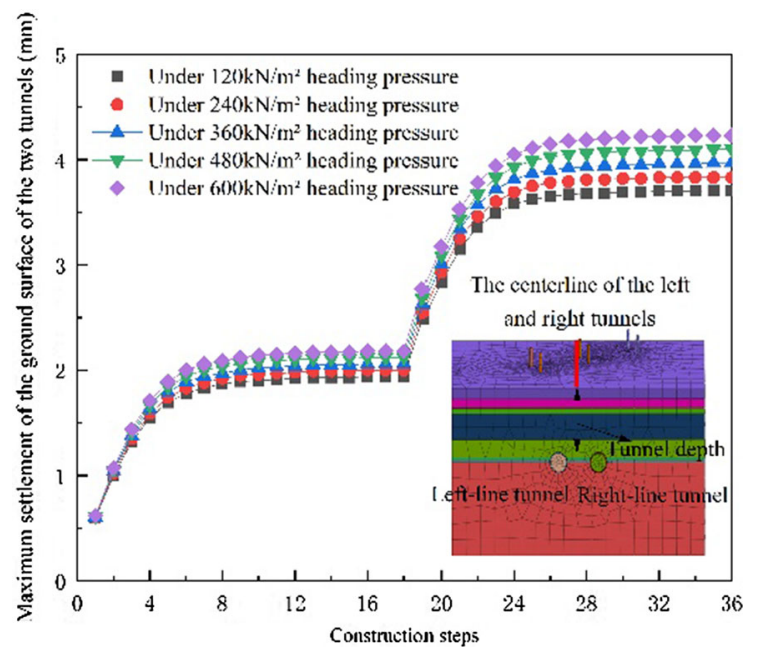

Fig. 13 Maximum surface settlement at the centerline of the left and right tunnels tunnels

Figure 15 shows that the cumulative subsidence of the surface decreases with the increase in driving pressure. The successively decreasing rates are $8.63 \%$, $9.20 \%, 10.11 \%$, and $11.28 \%$ at the same surface location. In practical engineering applications, the TBM driving pressure should be increased to maximize the economic effect and to reduce the surface subsidence and the impact on the surface structures.

\subsection{Analysis of Vertical Displacement of Abutment Pile Foundation}

The vertical displacement cloud diagram of the pile foundation of the overpass under different driving pressures is shown in Fig. 16.

It can be seen from Fig. 16 that the values of the vertical displacement vary with driving pressure. The maximum displacement values at driving pressures of $120 \mathrm{kN} / \mathrm{m}^{2}, 240 \mathrm{kN} / \mathrm{m}^{2}, 360 \mathrm{kN} / \mathrm{m}^{2}, 480 \mathrm{kN} / \mathrm{m}^{2}$, and $600 \mathrm{kN} / \mathrm{m}^{2}$ are $-1.01 \mathrm{~mm},-0.93 \mathrm{~mm},-0.86 \mathrm{~mm}$, $-0.78 \mathrm{~mm}$, and $-0.70 \mathrm{~mm}$, respectively. The minimum displacement values are $-4.06 \mathrm{~mm}$, $-3.98 \mathrm{~mm}, \quad-3.91 \mathrm{~mm}, \quad-3.83 \mathrm{~mm}, \quad$ and $-3.76 \mathrm{~mm}$ corresponding to the above pressures. The negative sign indicates that the direction is downward, which refers to the settlement. While the vertical displacement under a driving pressure of 120 $\mathrm{kN} / \mathrm{m}^{2}$ has exceeded the safe limit for pile foundation settlement by $\pm 4 \mathrm{~mm}$, the value is not very large. The excavation of the new subway tunnel by the TBM process will lead to settlement of the pile foundation of the overpass; this does not meet the requirements of the actual engineering specification under the driving pressure of $120 \mathrm{kN} / \mathrm{m}^{2}$. By analyzing the settlement, it can be seen that as the driving pressure increases, the pile foundation settlement of the overpass decreases. From the values of the maximum settlement at different driving pressures, it can be seen that the rate of maximum settlement reduction is $2.01 \%, 1.79 \%$, $2.09 \%$, and $1.86 \%$, and irrespective of the value of the driving pressure, the maximum displacement appears at the position of the low pile cap. The minimum displacement appears at the pile foundation of pile pier No. 1 with the greatest length, and the second is at the pile foundation of pile pier No. 2 with the second greatest length. It shows that the deeper the pier is, the closer it is to the interval line from the excavation tunnel, and the greater is the effect of excavation on the pier. This is a key point that should be considered in the project (Cao and Zhuge 2013).

In the process of TBM excavation, the left and right tunnels are excavated through pile foundations No. 1, No. 2 , No. 3 , and No. 4 , in turn. The vertical settlement of the pile foundation caused by different driving pressures is shown in Figs. 17, 18, 19 and 20.

As can be seen from Figs. 17, 18, 19 and 20, the displacement curves of pile foundations of the piled bridge piers with different lengths and positions are different, and the trends of the vertical displacement curves of pile foundations No. 1, No. 2, and No. 4 are similar. With the progress of construction steps, the changes in vertical displacement stabilize first, and then accelerate; subsequently, the changes continue gradually, and finally accelerate again. The pile foundations No. 1 and No. 4 are approximately in a vertical plane. The effect of the TBM excavation on these foundations is similar. However, the lengths of the two pile foundations from the excavation surface of the subway are different. The pile foundation No. 1 is closer to the excavation tunnel, and hence its final vertical settlement is greater than that of pile foundation No. 4. Thus, the pile foundation close to the tunnel section line should be paid more attention during construction. For pile foundations No. 1 and No. 2, the length is greater, and they are located near the centerline of the left and right tunnels. The construction of the left and right lines has the same effect on pile foundations No. 1 and No. 2, but pile foundation No. 2 is relatively short in length, and hence the final 


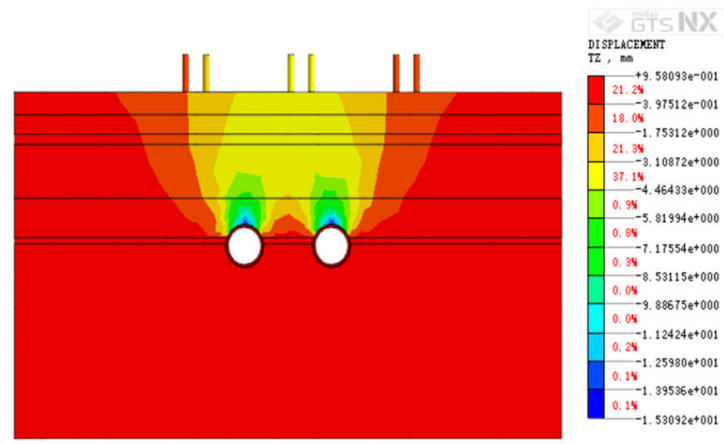

(a)Cloud map of vertical displacement under driving

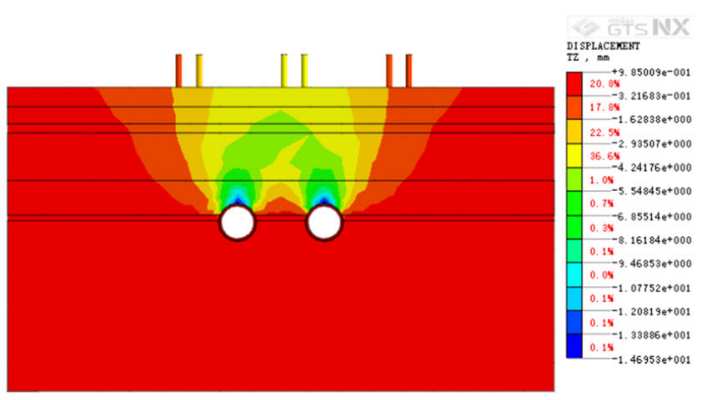

(c) Cloud map of vertical displacement under driving pressure of $360 \mathrm{kN} / \mathrm{m}^{2}$

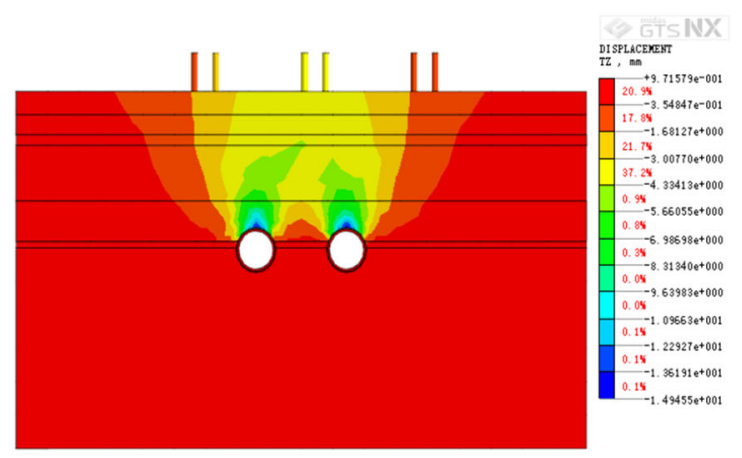

(b) Cloud map of vertical displacement under driving

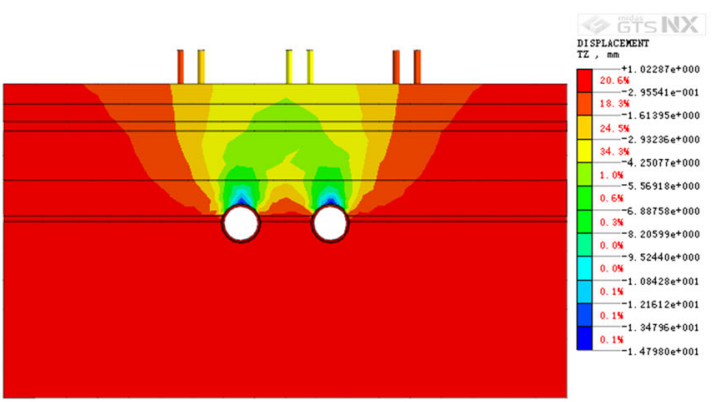

(d) Cloud map of vertical displacement under driving pressure of $480 \mathrm{kN} / \mathrm{m}^{2}$

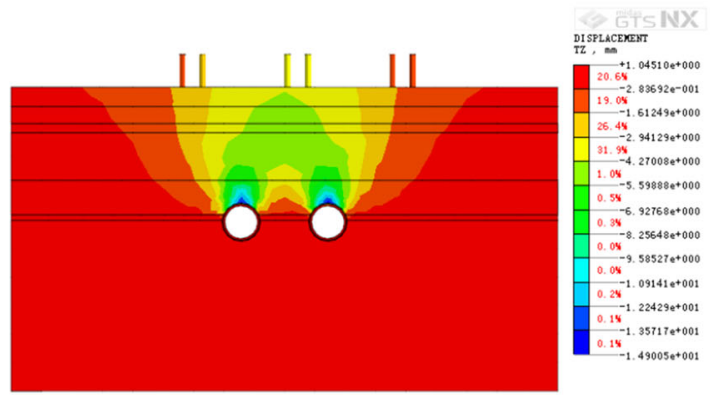

(e) Cloud map of vertical displacement under driving pressure of $600 \mathrm{kN} / \mathrm{m}^{2}$

Fig. 14 Cloud map of vertical displacement under different driving pressures

settlement value is less than that in the case of pile foundation No. 1. For the vertical displacement curves of piles No. 1, No. 2, and No. 4, the settlement values increase significantly at the twenty-fifth step of construction. Considering that the left-line excavation is conducted before the right-line excavation, it can be concluded that the effect of the right-line construction on the pile foundation is greater than that of the leftline construction. The final settlement values of pile foundations No. 1, No. 2, and No. 4 are greater than that of pile foundation No. 3, and hence special attention should be paid to the change in the pile foundation settlement of pile column piers No. 1, No. 2, and No. 4 overpass during the right-line tunnel excavation. The vertical displacement of pile column pier No. 3 increases first and then becomes smooth until the final settlement value is approximately $2 \mathrm{~mm}$, which is far less than the safe limit for pile foundation 


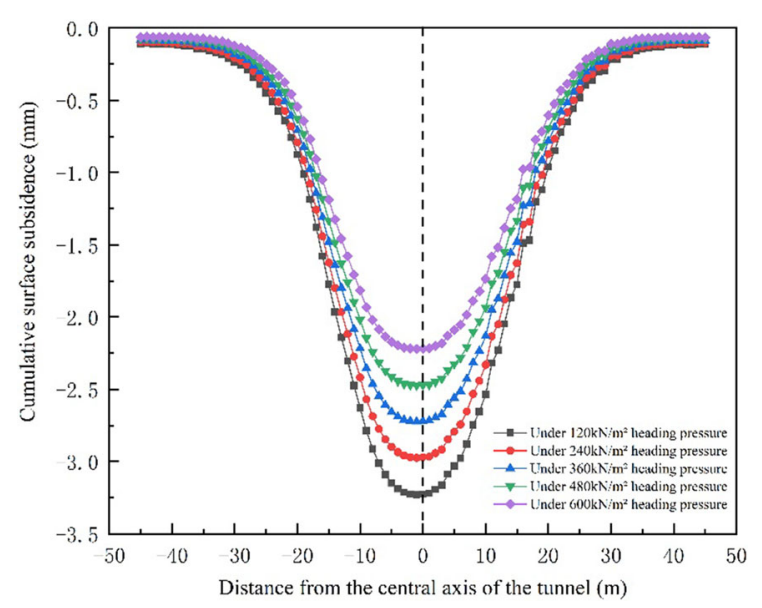

Fig. 15 Accumulated surface settlement map

settlement $( \pm 4 \mathrm{~mm})$. For the vertical displacement curves of the pile foundations under different driving pressures, the foundations of piles No. 2 and No. 4 show significant changes in settlement values under different driving pressures, indicating that pile foundations No. 2 and No. 4 are more sensitive to changes in driving pressure; irrespective of the pile foundation, with the increase in driving pressure, the settlement value decreases.

\subsection{Shield Fuselage Vibration Analysis}

\subsubsection{Vibration Control Specifications}

To date, no specific control standard has been established for the vibrations during TBM construction in China. To evaluate the effect of the vibrations on the structures, the main vibration frequency and peak vibration speed are normally used in China and other countries. Blasting safety regulations provide the allowable particle vibration speed of various building structures in different main vibration frequency ranges. With reference to this standard, a safety assessment of TBM construction vibration is conducted as follows (Avunduk and Copur 2019).

\subsubsection{Analysis of Simulation Results}

The velocity curves in the vertical ( $\mathrm{Vy}$ ) and horizontal $\left(\mathrm{V}_{\mathrm{X}}\right)$ directions at section $\mathrm{DC} 2$ in the ground are shown in Fig. 21.
The vertical vibration velocity is the smallest near the central axis of the two tunnels, and the largest above the respective tunnels. The maximum vibration speed is $3.32 \mathrm{~mm} / \mathrm{s}$ near the left line and $1.94 \mathrm{~mm} / \mathrm{s}$ near the right line; the speeds gradually decrease toward both sides. The horizontal vibration velocity is the largest near the left tunnel with a maximum value of $12.13 \mathrm{~mm} / \mathrm{s}$, which decreases gradually toward both sides. The horizontal vibration speed is always greater than the vertical vibration speed, and the maximum vibration speed does not exceed the general civil building requirement of $20 \mathrm{~cm} / \mathrm{s}$. Therefore, the ground vibration speed caused by tunneling is within the safe range; thus, the horizontal vibration plays a key role. In practical engineering applications, the impact of the horizontal vibration on surface vibration should be considered.

Points DC3 and DC4 at the upper and lower parts of the surrounding rock of the right-line tunnel are studied to analyze the effect of the vibration caused by TBM tunneling on the surrounding rock soil. Figure 22 shows the curve of the vibration speed at DC3 and DC4, on the surface with the construction time. The vibration of the TBM excavation greatly influences the surrounding rock of the upper and lower tunnels. With continued excavation, the vibration speed shows the same increasing trend. The rate of increase of vibration speed is the highest in the first $1000 \mathrm{~s}$ and gradually decreases thereafter. The upper part receives a larger impact (higher by $1.5 \%$ ) than the lower part. In actual construction, the upper surrounding rock vibration support must be considered to prevent hidden safety hazards.

\section{Conclusion}

In this work, referring to the TBM construction of Qingdao Metro Line 1 in the Haixiao section, the measured data and numerical simulation results are compared to confirm the reliability of the simulation, and a sensitivity analysis is performed on ground subsidence and surrounding environment under different construction parameters by using the constitutive model. The following conclusions are drawn.

(1) In the TBM construction, different driving speeds have varying effects on the surface. When the other driving parameters are 


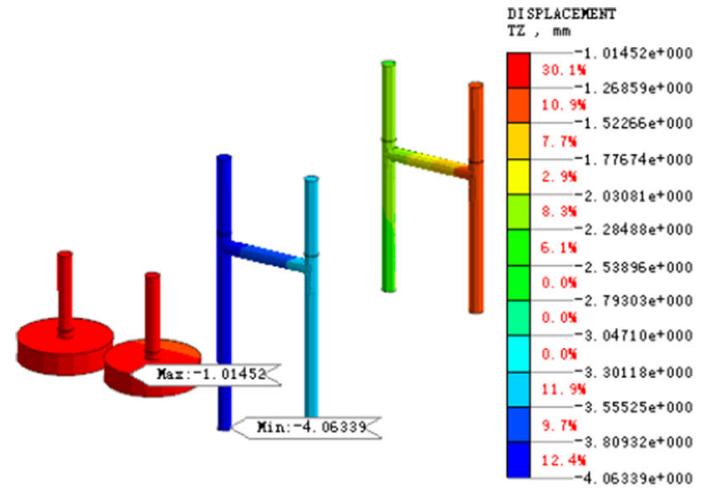

(a) Cloud map of vertical displacement under driving pressure of $120 \mathrm{kN} / \mathrm{m}^{2}$

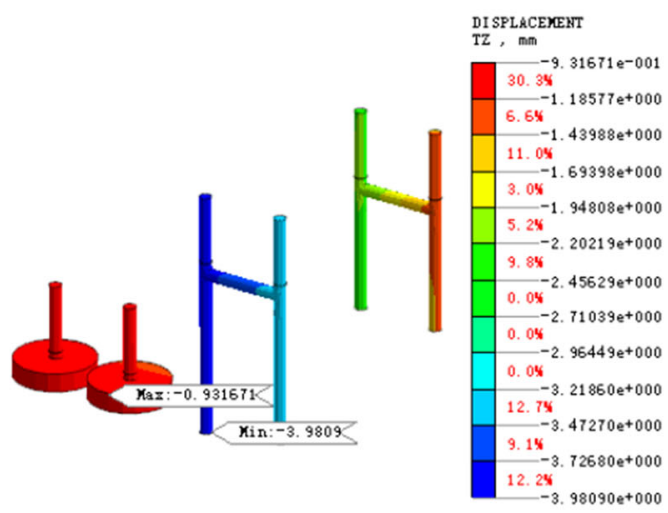

(b) Cloud map of vertical displacement under driving pressure of $240 \mathrm{kN} / \mathrm{m}^{2}$

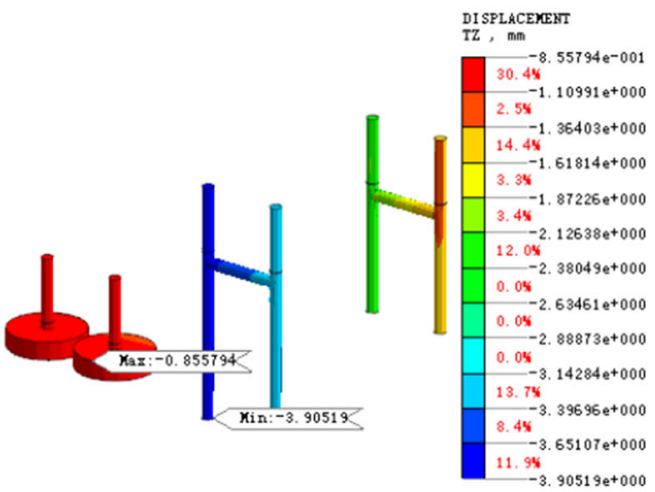

(c) Cloud map of vertical displacement under driving pressure of $360 \mathrm{kN} / \mathrm{m}^{2}$

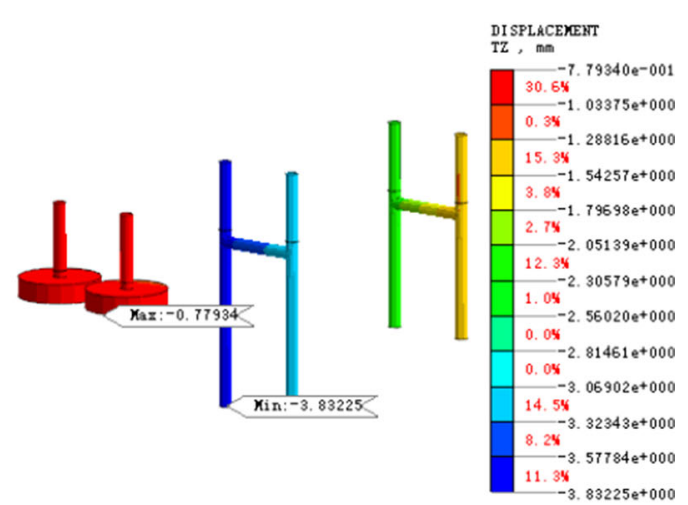

(d) Cloud map of vertical displacement under driving pressure of $480 \mathrm{kN} / \mathrm{m}^{2}$

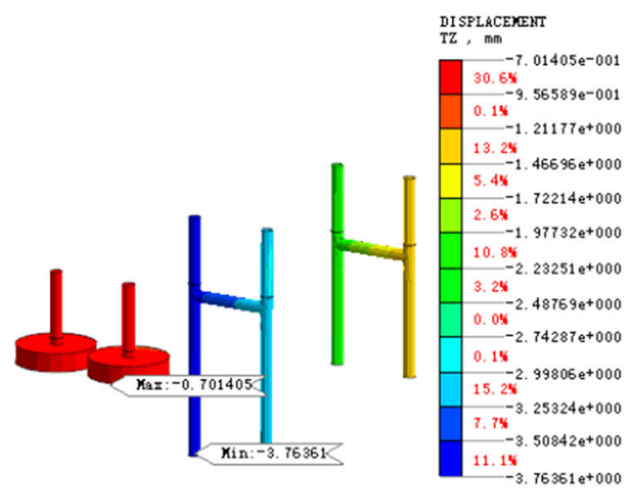

(e) Cloud map of vertical displacement under driving pressure of $600 \mathrm{kN} / \mathrm{m}^{2}$ 
4Fig. 16 Cloud map of vertical displacement of pile foundation of overpass

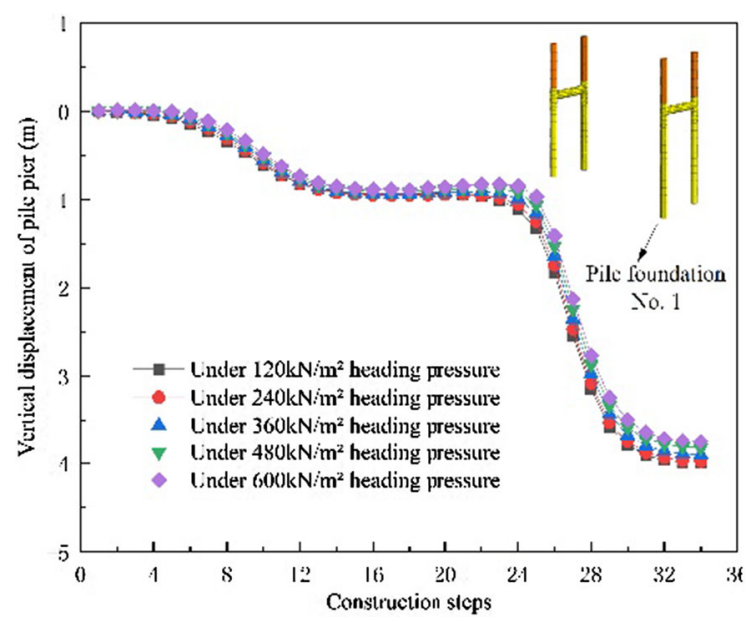

Fig. 17 Vertical displacement of pile foundation No.1

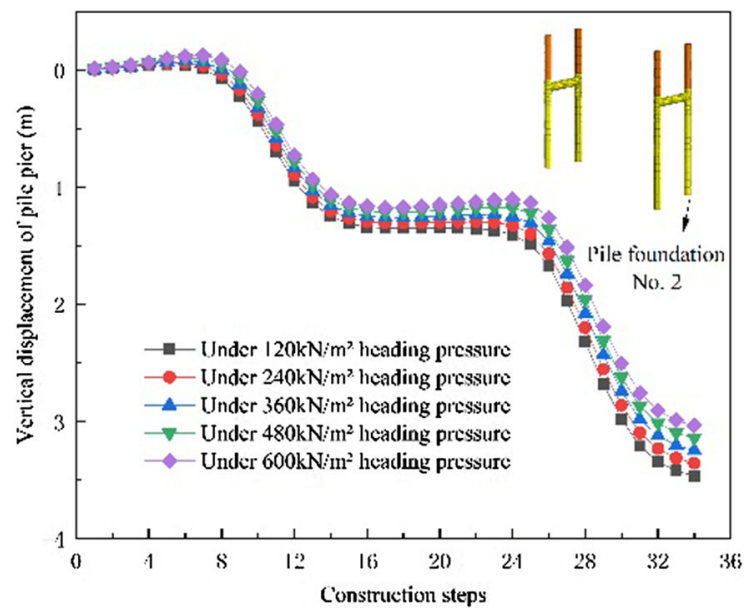

Fig. 18 Vertical displacement of pile foundation No.2

controlled, the settlement is small when the driving speed is high. To maximize the economic benefits, the digging speed should be increased so that the ground subsidence and impact on the ground structures are reduced.

(2) For the construction of the double-line shield tunnel, the left-line construction is carried out first, and then the right-line construction. With the construction of the left-line tunnel, the surface settlement on the center line of the left-line tunnel is greater than the surface

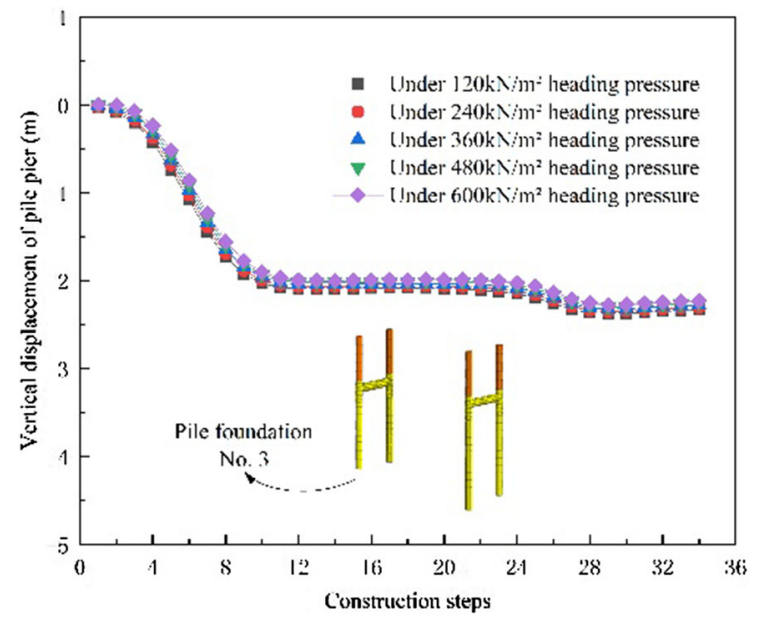

Fig. 19 Vertical displacement of pile foundation No. 3

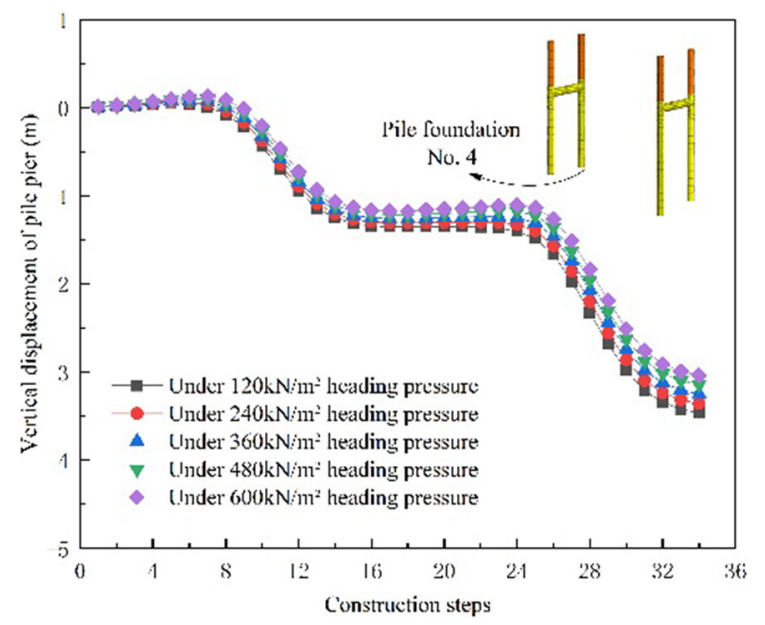

Fig. 20 Vertical displacement of pile foundation No. 4

settlement on the center line of the right-line tunnel; after the construction is completed, the surface settlement value tends to stabilize; when the right-line tunnel is being excavated, the right-line tunnel excavated afterwards will continue to cause the settlement of the surface soil in the center line of the left-line tunnel, and the left-line tunnel that has been excavated will change the displacement field of the rock and soil around the right-line tunnel, which will have a certain impact on the construction of the right-line tunnel, causing the ground settlement during the construction of the right-line tunnel to be significantly greater than that of the singleline tunnel. For tunnel excavation, the mutual 


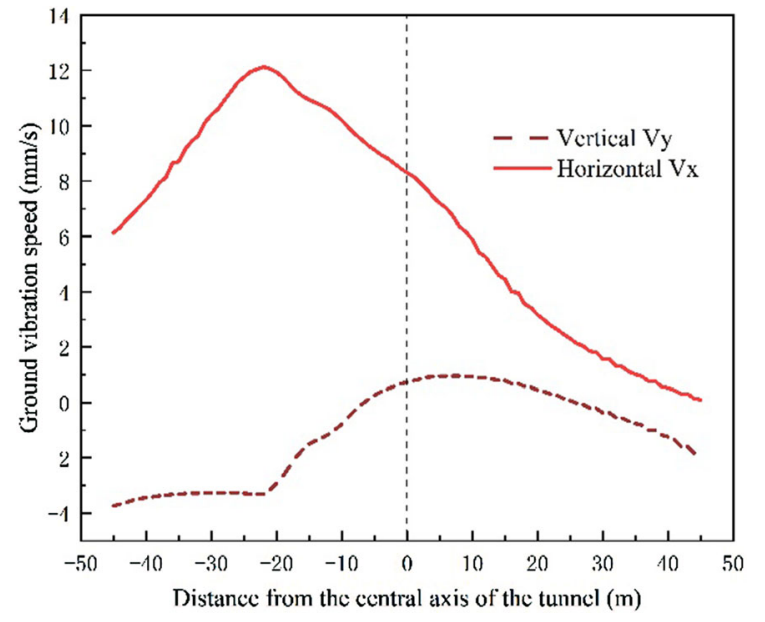

Fig. 21 Curve of surface vibration speed

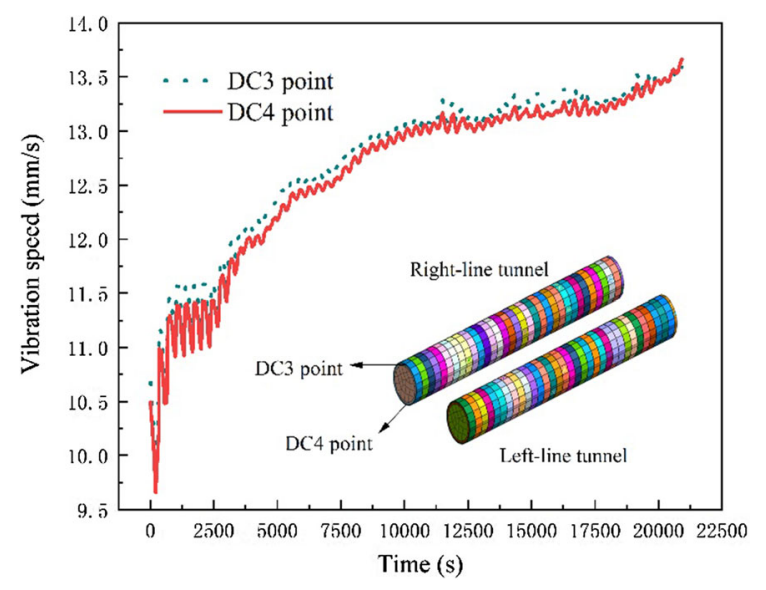

Fig. 22 Vibration speed curves at DC3 and DC4

disturbance effect of double-track shield excavation is obvious. The double-line shield construction has the strongest effect on the surface settlement value of the double-line tunnel.

(3) Different tunneling pressures have varying effects on the surface. Within a certain range, the settlement is small when the tunneling pressure is high. In practical engineering applications, the TBM driving pressure should be increased to maximize the economic effect and reduce the surface subsidence and the impact on the surface building.

(4) For TBM construction of subway tunnels passing through pile-type piers, the closer the piers are to the excavation tunnel section line, the greater the impact of excavation on the piers.
Special attention should be paid to this key point in the project. During the construction, special attention should be paid to the pile foundation near the tunnel section line.

(5) The horizontal vibration velocity caused by the TBM construction in this geological environment is always greater than the vertical velocity, and the maximum vibration velocity does not exceed the requirement of $20 \mathrm{~mm} / \mathrm{s}$ for general civil buildings. The vibration caused by TBM excavation greatly affects the upper and lower surrounding rocks of the tunnel. The vibration effect basically shows an increasing trend with the impact on the upper side approximately $1.5 \%$ larger than that on the lower side.

Open Access This article is licensed under a Creative Commons Attribution 4.0 International License, which permits use, sharing, adaptation, distribution and reproduction in any medium or format, as long as you give appropriate credit to the original author(s) and the source, provide a link to the Creative Commons licence, and indicate if changes were made. The images or other third party material in this article are included in the article's Creative Commons licence, unless indicated otherwise in a credit line to the material. If material is not included in the article's Creative Commons licence and your intended use is not permitted by statutory regulation or exceeds the permitted use, you will need to obtain permission directly from the copyright holder. To view a copy of this licence, visit http://creativecommons.org/licenses/by/4.0/.

\section{References}

Arbabsiar MH, Ebrahimi Farsangi MA, Mansouri H (2020) A new model for predicting the advance rate of a tunnel boring machine (Tbm) in hard rock conditions. RudarskoGeološko-Naftni Zbornik 35:57-74. https://doi.org/10. 17794/rgn.2020.2.6

Avunduk E, Copur H (2019) Effect of Clogging on EPB TBM performance: a case study in Akfirat waste water Tunnel, Turkey. Geotech Geol Eng 37:4789-4801. https://doi.org/ 10.1007/s10706-019-00938-6

Aygar EB (2020) Evaluation of new Austrian tunnelling method applied to Bolu tunnel's weak rocks. J Rock Mech Geotech Eng 12:541-556. https://doi.org/10.1016/j.jrmge.2019.12. 011

Bahrainy H, Khosravi H (2013) The impact of urban design features and qualities on walkability and health in underconstruction environments: the case of Hashtgerd New Town in Iran. Cities 31:17-28. https://doi.org/10.1016/j. cities.2013.01.001

Cao YH, Zhuge AJ (2013) Effect of shield tunneling on existent piles in soft soil area. Adv Mater Res 671-674:1093-1097. 
https://doi.org/10.4028/www.scientific.net/AMR.671-674. 1093

Faramarzi L, Kheradmandian A, Azhari A (2020) Evaluation and optimization of the effective parameters on the shield TBM performance: Torque and Thrust-using discrete element method (DEM). Geotech Geol Eng 38:2745-2759. https://doi.org/10.1007/s10706-020-01183-y

Hasanpour R, Schmitt J, Ozcelik Y, Rostami J (2017) Examining the effect of adverse geological conditions on jamming of a single shielded TBM in Uluabat tunnel using numerical modeling. J Rock Mech Geotech Eng 9:1112-1122. https://doi.org/10.1016/j.jrmge.2017.05.010

Komu MP, Guney U, Kilickaya TE, Gokceoglu C (2019) Using 3D numerical analysis for the assessment of tunnel-landslide relationship: Bahce-Nurdag tunnel (South of Turkey). Geotech Geol Eng 38:1237-1254. https://doi.org/10.1007/ s10706-019-01084-9

Kwak C-W, Park I-J (2015) Numerical simulation for surface settlement considering face vibration of TBM tunnelling in mixed-face condition. J Korean Tunn Undergr Space Assoc 17:333-339. https://doi.org/10.9711/ktaj.2015.17.3. 333

Li C, Tiedemann J, Zhou HW (2012) Quantitative analysis of several influencing factors on TBM advance speed. Adv Mater Res 594-597:1318-1323. https://doi.org/10.4028/ www.scientific.net/AMR.594-597.1318

Ling J, Sun W, Yang X, Tong X, Zhang N (2018) Vibration response and parameter influence of TBM cutterhead system under extreme conditions. J Mech Sci Technol 32:4959-4969. https://doi.org/10.1007/s12206-018-09448

Liu C, Peng Z, Pan L, Liu H, Yang Y, Chen W, Jiang H (2020) Influence of tunnel boring machine (TBM) advance on adjacent tunnel during ultra-rapid underground pass (URUP) tunneling: a case study and numerical investigation. Appl Sci. https://doi.org/10.3390/app10113746

Liu Q, Huang X, Gong Q, Du L, Pan Y, Liu J (2016) Application and development of hard rock TBM and its prospect in China. Tunn Undergr Space Technol 57:33-46. https://doi. org/10.1016/j.tust.2016.01.034

Lv JL, Jiang Y (2012) Mechanism analysis of the impact on Chinese Urban rail transit construction on the surrounding real estate prices. Appl Mech Mater 178-181:1866-1869. https://doi.org/10.4028/www.scientific.net/AMM.178181.1866

Nagel F, Meschke G (2011) Grout and bentonite flow around a TBM: computational modeling and simulation-based assessment of influence on surface settlements. Tunn
Undergr Space Technol 26:445-452. https://doi.org/10. 1016/j.tust.2010.12.001

Namli M, Aras F (2020) Investigation of effects of dynamic loads in metro tunnels during construction and operation on existing buildings. Arab J Geosci. https://doi.org/10.1007/ s12517-020-05456-X

Pirastehfar K, Shivaei S, Sadaghiani MH, Nikooee E (2020) 3D numerical investigation of the effects of driving of the new mechanized tunnel on existing segmental linings and ground surface settlements - a case study: Shiraz metro line 2. Int J Geotech Eng. https://doi.org/10.1080/19386362. 2020.1816381

Rezaei AH, Ahmadi-adli M (2020) The volume loss: real estimation and its effect on surface settlements due to excavation of tabriz metro tunnel. Geotech Geol Eng 38:2663-2684. https://doi.org/10.1007/s10706-01901177-5

Sun B, Yang S (2019) An improved 3D finite difference model for simulation of double shield TBM tunnelling in heavily jointed rock masses: the DXL tunnel case. Rock Mech Rock Eng 52:2481-2488. https://doi.org/10.1007/s00603018-1730-8

Wu L, Guan T, Lei L (2013) Discrete element model for performance analysis of cutterhead excavation system of EPB machine. Tunn Undergr Space Technol 37:37-44. https:// doi.org/10.1016/j.tust.2013.03.003

Wu Z, Jiang Y, Liu Q, Ma H (2018) Investigation of the excavation damaged zone around deep TBM tunnel using a Voronoi-element based explicit numerical manifold method. Int J Rock Mech Min Sci 112:158-170. https://doi. org/10.1016/j.ijrmms.2018.10.022

Yang H, Shi H, Jiang X, Liu C, Yu L (2020) Study on influence of construction process of double-line shield tunnels on frame structure. Geotech Geol Eng. https://doi.org/10. 1007/s10706-020-01569-y

Yang S-Q, Tao Y, Xu P, Chen M (2019) Large-scale model experiment and numerical simulation on convergence deformation of tunnel excavating in composite strata. Tunn Undergr Space Technol. https://doi.org/10.1016/j.tust. 2019.103133

Zhang K, Yu H, Liu Z, Lai X (2010) Dynamic characteristic analysis of TBM tunnelling in mixed-face conditions. Simul Model Pract Theory 18:1019-1031. https://doi.org/ 10.1016/j.simpat.2010.03.005

Publisher's Note Springer Nature remains neutral with regard to jurisdictional claims in published maps and institutional affiliations. 